Fifth International Conference on Sustainable Construction Materials and

Technologies. http://www.claisse.info/Proceedings.htm

\title{
EFFECTS OF DRYING SHRINKAGE OF CONCRETE ON SHEAR BEHAVIOUR OF REINFORCED CONCRETE BEAM
}

\author{
Hikotsugu Hyodo $^{1}$, Ryoichi Sato ${ }^{2}$, Kenji Kawai ${ }^{2}$ and Ken-ichiro Nakarai ${ }^{2}$ \\ ${ }^{1}$ Taiheiyo Cement Corporation, Central Research Laboratory \\ 2-4-2, Osaku, Sakura City, Chiba Prefecture, 285-8655 Japan \\ hikotsugu_hyoudou@taiheiyo-cement.co.jp \\ ${ }^{2}$ Hirosihma University \\ 1-4-1, Kagamiyama, Higashi-hiroshima City, Hiroshima Prefecture, 739-8527 Japan \\ sator@hiroshima-u.ac.jp \\ kkawai@hiroshima-u.ac.jp \\ nakarai@hiroshima-u.ac.jp
}

\begin{abstract}
In order to investigate the effects of drying shrinkage of concrete on shear tension strength of normal-strength reinforced concrete (RC) beam without web reinforcement, the loading test of RC beams was carried out. Major factors were the effective depth of 250,500 and $1000 \mathrm{~mm}$ as well as the concrete shrinkage. Twelve RC beams were prepared where half beams were sealed and the others were exposed to the air in a room to accelerate shrinkage. Test results showed that the drying shrinkage of concrete decreased the shear tension strength of RC beams as well as enhanced its size effect. Based on the results, a mechanism of the coupling effects of drying shrinkage and effective depth on the shear tension strength of RC beam was proposed. In addition, a concept based on equivalent tension reinforcement ratio incorporating the effect of drying shrinkage in concrete was effective in evaluating the shear tension strength.
\end{abstract}

Keywords. Reinforced concrete beam without web reinforcement, Shear tension strength, Size effect, Drying shrinkage, Equivalent tension reinforcement ratio

\section{INTRODUCTION}

Drying shrinkage of concrete often induces cracking in RC members, which may result in deterioration of durability in concrete structures. The mechanisms of drying shrinkage, risk of cracking, control method of shrinkage, and so on have been studied by many researchers. Effect of concrete shrinkage on ultimate capacity of RC member has been also studied. Hasegawa and Seki (1984) reported the restrained stress and cracks due to drying shrinkage hardly affected the flexural capacity, because flexural 
failure occurs after yielding of reinforcement, and the strain of steel bars at failure is much larger than shrinkage strain in concrete.

On the other hand, shear failure often occurs when the strain of reinforcing bars is at an elastic stage. In this respect, shear capacity is relatively affected by concrete shrinkage. Sato and Kawakane (2008) reported the shear tension strength of highstrength RC beam decreases with increase of autogenous shrinkage in concrete. In addition, a new design equation for estimating shear tension strength, which was formulated based on a concept of "equivalent tension reinforcement ratio" considering the strain change of tension reinforcing bars before and after loading was proposed.

This paper presents the effects of drying shrinkage on shear tension strength of normalstrength RC beam without web reinforcement as well as its size effect. This paper includes a part of the authors' publication (Hyodo et al. 2017), but the effects of drying shrinkage and reinforcement ratio on the shear tension strength are more deeply discussed.

\section{OUTLINE OF EXPERIMENTS}

\section{Materials and Mixture Proportions}

Table 1 lists the types of materials used in this study. Table 2 tabulates the mixture proportions of the concretes prepared in this study. Ordinary Portland cement was used. Fine and coarse aggregates were crashed sand and stone from same site. They were selected as aggregates showing large shrinkage. Preliminary measurements using prism specimens $(100 \mathrm{~mm} \times 100 \mathrm{~mm} \times 400 \mathrm{~mm})$ under $20^{\circ} \mathrm{C}$ and $60 \% \mathrm{R}$.H. based on JIS A 1129 showed $1146 \mu$ of shrinkage after drying for 6 months. The maximum size of coarse aggregate was $20 \mathrm{~mm}$. The water-to-cement ratio (W/C) was set at $50 \%$. High strength deformed steel bar $\left(f_{y} 1080 \mathrm{~N} / \mathrm{mm}^{2}\right)$ was used to induce shear failure in reinforced concrete before yielding of tension reinforcing bars.

Table 1 Materials

\begin{tabular}{|c|c|c|}
\hline Materials & Symbol & Types/ Properties \\
\hline Water & $\mathrm{W}$ & Industrial water \\
\hline Cement & $\mathrm{C}$ & Ordinary portland cement, Density: $3.16 \mathrm{~g} / \mathrm{cm}^{3}$ \\
\hline Fine aggregate & $\mathrm{S}$ & Density: $2.65 \mathrm{~g} / \mathrm{cm}^{3}$, Absorption: $1.86 \%$ \\
\hline Coarse aggregate & $\mathrm{G}$ & $\begin{array}{c}\text { Density: } 2.69 \mathrm{~g} / \mathrm{cm}^{3}, \text { Absorption: } 0.89 \% \\
\text { Maximum size: } 20 \mathrm{~mm}\end{array}$ \\
\hline Chemical admixture & - & Polycarboxylic acid-based superplasticizer \\
\hline
\end{tabular}

Table 2 Mixture proportions

\begin{tabular}{c|c|c|c|c|c|c|c|c|c}
\hline \multirow{3}{*}{ Series } & \multirow{2}{*}{$\begin{array}{c}\text { Curing } \\
\text { condition } \\
\text { before loading }\end{array}$} & $\begin{array}{c}\text { Slump } \\
(\mathrm{cm})\end{array}$ & $\begin{array}{c}\text { Targeted value } \\
\text { Content } \\
(\%)\end{array}$ & \multirow{2}{*}{$\begin{array}{c}\text { W/C } \\
(\%)\end{array}$} & $\begin{array}{c}\text { s/a } \\
(\%)\end{array}$ & W & $\mathrm{C}$ & $\mathrm{S}$ & $\mathrm{G}$ \\
\hline $\mathrm{HS}$ & Drying & $10 \pm 2.5$ & $4.5 \pm 1.5$ & 50 & 46.4 & 170 & 340 & 832 & 977 \\
\hline
\end{tabular}




\section{LS}

Sealed

\section{Specimens}

Table 3 outlines dimensions of the RC beam specimens. The size and dimension of $\mathrm{RC}$ beams as well as main reinforcing bars used in the present study are shown in Figure 1(a). Three different sizes of RC beams without shear reinforcement were prepared. The effective depths of RC beams were $250 \mathrm{~mm}, 500 \mathrm{~mm}$ and $1000 \mathrm{~mm}$. In all specimens, breadth was $300 \mathrm{~mm}$, shear span-to-effective depth ratio was 3.0, and tensile reinforcement ratios were around $1 \%\left(p_{s}=A_{s} / b d=1.03 \%-1.06 \%\right.$, where $p_{s}$ is the nominal tension reinforcement ratio and $A_{s}$ is area of tensile reinforcement). After concrete casting, top surfaces were sealed with polyester films and curing sheets until the demolding at the age of 7 days. After demolding at 7 days, in the case of LS, the specimens were continuously cured under sealed condition with aluminium tapes to prevent drying shrinkage. In the case of HS, the specimens were exposed to the air in a room to accelerate shrinkage. Average relative humidity in the room was ranging from $64.4 \%$ to $66.3 \%$. The specimens were cured for about 100-300 days to have appropriate compression strains in reinforcements for loading tests.

Table 3 Outline of RC beams

\begin{tabular}{|c|c|c|c|c|c|c|c|c|}
\hline Symbol & $\begin{array}{c}d \\
(\mathrm{~mm})\end{array}$ & $\begin{array}{c}h \\
(\mathrm{~mm})\end{array}$ & $\begin{array}{c}L \\
(\mathrm{~mm})\end{array}$ & $\begin{array}{c}c \\
(\mathrm{~mm})\end{array}$ & $\begin{array}{c}a \\
(\mathrm{~mm})\end{array}$ & $\begin{array}{c}b \\
(\mathrm{~mm})\end{array}$ & $a / d$ & $\begin{array}{c}p_{s} \\
(\%) \\
\end{array}$ \\
\hline $\mathrm{d} 250$ & 250 & 305 & 2300 & 200 & 750 & \multirow{3}{*}{300} & \multirow{3}{*}{3.0} & $\begin{array}{c}1.03 \\
\text { (2D22) }\end{array}$ \\
\hline $\mathrm{d} 500$ & 500 & 580 & 4500 & 500 & 1500 & & & $\begin{array}{c}1.06 \\
\text { (2D32) }\end{array}$ \\
\hline $\mathrm{d} 1000$ & 1000 & 1130 & 7500 & 500 & 3000 & & & $\begin{array}{c}1.06 \\
\text { (4D32) }\end{array}$ \\
\hline
\end{tabular}

$d$ : Effective depth of beam, $h$ : Height of beam, $L$ : Length of beam, $c$ : Distance between two loadingpoints, $a$ : Shear span length, $b$ : Breadth of beam, $p_{s}$ : Tension reinforcement ratio $\left(=A_{s} / b d\right), A_{s}$ : Cross-section area of tension reinforcement

Plain concrete specimens having same cross-sections as the RC beam specimens were also prepared to measure free shrinkage of the concrete. The length of the prism specimens was $1000 \mathrm{~mm}$. After demolding at the age of 7 days, all surfaces of LS specimens and both edge faces of HS specimens were sealed by aluminium tape as shown in Figure 1(b).

Cylindrical specimens of dimensions $\varphi 100 \times 200 \mathrm{~mm}$ for compressive strength and Young's modulus, as well as those of dimensions $\varphi 150 \times 200 \mathrm{~mm}$ for splitting tensile strength were prepared. All the specimens were cured in the same conditions as the RC beams.

\section{Loading and Measurement}

All the RC beams were loaded monotonically with two incremental concentrated loads. Deflections at the centre section of the RC beam was measured by displacement transducers. Vertical, horizontal and diagonal displacement in the shear span were also measured by displacement transducers attached on the L-shaped aluminium channels. 
Strain in tension reinforcing bar was measured by wire strain gauges just after concrete placement until completion of the loading tests. Crack width in shear span was measured by $\pi$ shaped displacement transducers. The compressive strength, splitting tensile strength and Young's modulus of concrete were measured at the age of loading test for RC beams.

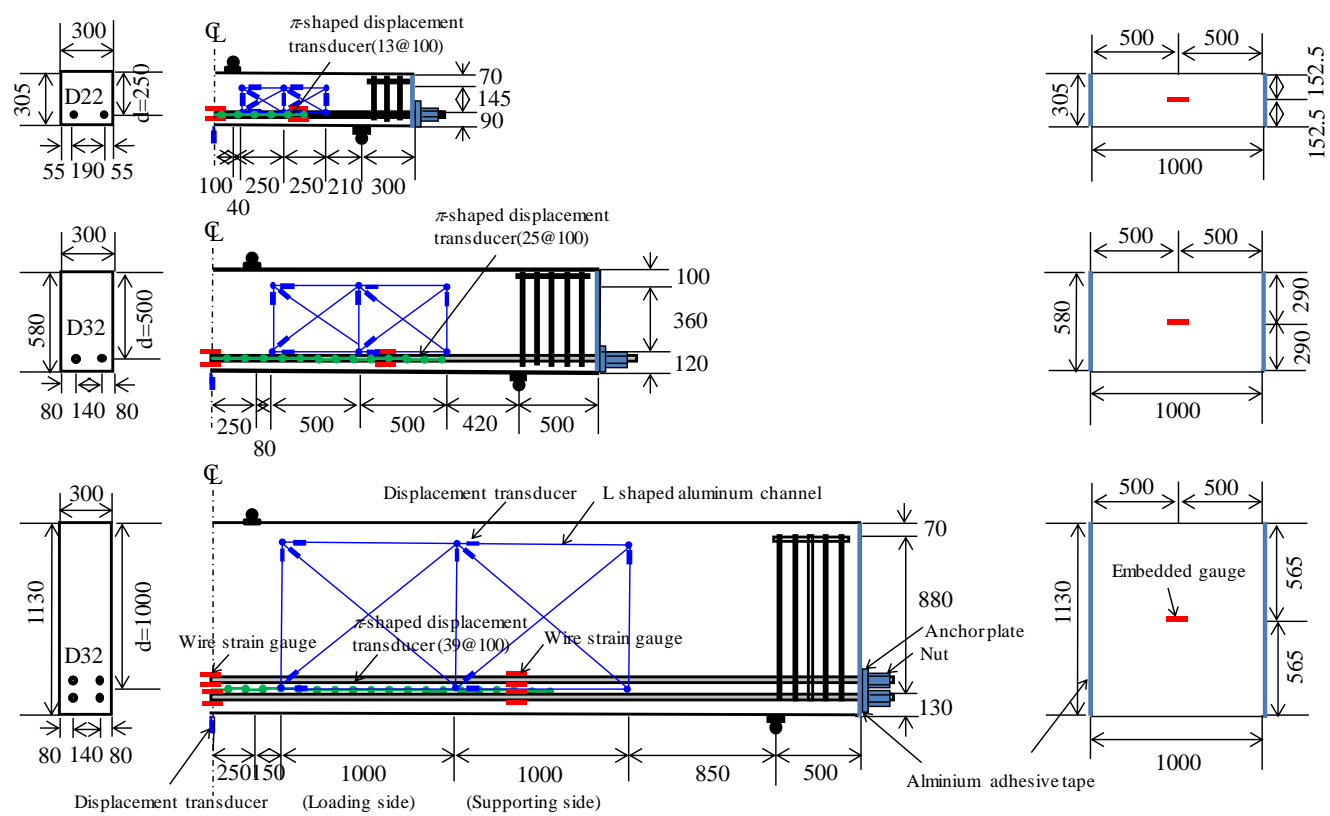

(a) RC beam specimen

(b)Plain concrete specimen

Figure 1 Dimensions and configuration of RC beam specimens and Specimens without reinforcement (unit: $\mathrm{mm}$ )

\section{EXPERIMENTAL RESULTS AND DISCUSSIONS}

\section{Mechanical Properties of Concrete}

Table 4 tabulates mechanical properties of concrete at the age of loading test. The compressive strength and the splitting tensile strength of concrete were not significantly different, regardless of the curing condition. On the other hand, Young's modulus of HS was lower by more than $15 \%$ as compared with that of LS.

Table 4 Mechanical properties of concrete

\begin{tabular}{c|l|c|c|c|c}
\hline \multirow{2}{*}{ Series } & \multirow{2}{*}{$\begin{array}{c}\text { Name of } \\
\text { specimen }\end{array}$} & $\begin{array}{c}\text { At the age of loading } \\
\text { (days) }\end{array}$ & \multicolumn{3}{|c}{ Mechanical properties } \\
\cline { 4 - 6 } & LS-250-A/B & $94 / 89$ & $f_{c}$ & $f_{t}$ & $E_{c}$ \\
\hline \multirow{3}{*}{ LS } & LS-500-A/B & $114 / 113$ & 39.6 & 3.1 & 25.2 \\
\cline { 2 - 6 } & LS-1000-A/B & $107 / 111$ & 40.5 & 3.2 & 25.3 \\
\hline \multirow{3}{*}{ HS } & HS-250-A/B & $121 / 129$ & 40.4 & 3.2 & 25.2 \\
\cline { 2 - 6 } & HS-500-A/B & $286 / 287$ & 43.0 & 3.0 & 21.4 \\
\cline { 2 - 6 } & HS-1000-A/B & $292 / 291$ & 43.1 & 3.1 & 21.5 \\
\hline
\end{tabular}

$f_{c}^{\prime}$ : Compressive strength $\left(\mathrm{N} / \mathrm{mm}^{2}\right), f_{t}$ : Splitting tensile strength $\left(\mathrm{N} / \mathrm{mm}^{2}\right), E_{c}$ : Young's modulus $\left(\mathrm{kN} / \mathrm{mm}^{2}\right)$ 


\section{Shrinkage}

Table 5 lists the strain in plain concrete, strain in tension reinforcement and stress in concrete at the bottom of RC beams before loading induced by shrinkage. The strain in plane concrete of LS and HS was around $100 \mu$ and 550-700 $\mu$ in shrinkage, respectively. The strain in tension reinforcement of LS and HS beams was around 25$70 \mu$ and $250-300 \mu$ in compression, respectively. The tensile stress in the concrete due to shrinkage of HS beams was by up to $1.3 \mathrm{~N} / \mathrm{mm}^{2}$ on average, while that of LS was almost zero.

Table 5 Outline of lording test results

\begin{tabular}{|c|c|c|c|c|c|c|c|c|}
\hline \multirow{3}{*}{ Series } & \multirow{3}{*}{$\begin{array}{l}\text { Name of } \\
\text { specimen }\end{array}$} & \multirow{3}{*}{$\begin{array}{c}\text { Strain in } \\
\text { plain } \\
\text { concrete }\end{array}$} & \multicolumn{6}{|c|}{$\mathrm{RC}$ beam specimen } \\
\hline & & & \multicolumn{3}{|c|}{$\begin{array}{l}\text { Strain and stress } \\
\text { before loading }\end{array}$} & \multicolumn{3}{|c|}{$\begin{array}{l}\text { Shear force and strength } \\
\text { at diagonal cracking }\end{array}$} \\
\hline & & & $\mathcal{E}_{s, \mathrm{def}}$ & $\sigma_{c, d e f}$ & $\mathcal{E}_{S 0, \mathrm{def}}$ & $V_{c}$ & $\tau_{c}$ & HS/LS \\
\hline \multirow{3}{*}{ LS } & $\begin{array}{l}\text { LS-250-A } \\
\text { LS-250-B }\end{array}$ & -86 & $\begin{array}{l}-26 \\
-24\end{array}$ & $\begin{array}{l}0.09 \\
0.09\end{array}$ & $\begin{array}{l}-29 \\
-27\end{array}$ & $\begin{array}{l}81 \\
88\end{array}$ & $\begin{array}{l}1.07 \\
1.18\end{array}$ & - \\
\hline & $\begin{array}{l}\text { LS-500-A } \\
\text { LS-500-B }\end{array}$ & -126 & $\begin{array}{l}-47 \\
-39\end{array}$ & $\begin{array}{l}0.21 \\
0.17\end{array}$ & $\begin{array}{l}-54 \\
-45\end{array}$ & $\begin{array}{l}130 \\
148\end{array}$ & $\begin{array}{l}0.87 \\
0.99\end{array}$ & - \\
\hline & $\begin{array}{l}\text { LS-1000-A } \\
\text { LS-1000-B }\end{array}$ & -137 & $\begin{array}{l}-73 \\
-57\end{array}$ & $\begin{array}{l}0.35 \\
0.28\end{array}$ & $\begin{array}{l}-86 \\
-67\end{array}$ & $\begin{array}{l}241 \\
232\end{array}$ & $\begin{array}{l}0.80 \\
0.77\end{array}$ & - \\
\hline \multirow{3}{*}{ HS } & $\begin{array}{l}\text { HS-250-A } \\
\text { HS-250-B }\end{array}$ & -629 & $\begin{array}{l}-291 \\
-288\end{array}$ & $\begin{array}{l}1.02 \\
1.01\end{array}$ & $\begin{array}{l}-335 \\
-332\end{array}$ & $\begin{array}{l}79 \\
78\end{array}$ & $\begin{array}{l}1.06 \\
1.05\end{array}$ & 0.94 \\
\hline & $\begin{array}{l}\text { HS-500-A } \\
\text { HS-500-B }\end{array}$ & -700 & $\begin{array}{l}-307 \\
-302\end{array}$ & $\begin{array}{l}1.33 \\
1.31\end{array}$ & $\begin{array}{l}-363 \\
-357\end{array}$ & $\begin{array}{l}140 \\
131\end{array}$ & $\begin{array}{l}0.93 \\
0.87\end{array}$ & 0.97 \\
\hline & $\begin{array}{l}\text { HS-1000-A } \\
\text { HS-1000-B }\end{array}$ & -569 & $\begin{array}{l}-234 \\
-246\end{array}$ & $\begin{array}{l}1.11 \\
1.17\end{array}$ & $\begin{array}{l}-280 \\
-295\end{array}$ & $\begin{array}{l}198 \\
208\end{array}$ & $\begin{array}{l}0.66 \\
0.69\end{array}$ & 0.86 \\
\hline
\end{tabular}

$\varepsilon_{c}$ : Strain in plain concrete specimen $(\mu)\left(-:\right.$ shrinkage, + : expansion), $\varepsilon_{s, d e f}$ : Tension reinforcement strain induced by shrinkage of concrete $(\mu)\left(-:\right.$ shrinkage, + : expansion), $\sigma_{c, \text { def: }}$ Stress in concrete at the bottom of RC beams induce by shrinkage $\left(\mathrm{N} / \mathrm{mm}^{2}\right)$ (+: tension, -: compression), $\varepsilon_{s 0, d e f}$ : Tension reinforcement strain when concrete stress at the depth of reinforcement is zero (+: tension, -: compression), $V_{c}$ : Shear force at diagonal cracking $(\mathrm{kN}), \tau_{c}$ : Shear tension strength $\left(\mathrm{N} / \mathrm{mm}^{2}\right)$ $\left(=V_{c} / b d\right), \mathrm{HS} / \mathrm{LS}$ : Ratio of shear tension strength of HS beam to that of LS beam

\section{Load-Deflection Relationship}

The relationship between load and deflection of RC beams are shown in Figure 2. The circler mark shown in figure denote the primary diagonal cracking. As shown in this figure, the deflection of LS beams is obviously smaller than those of HS beams up to the diagonal cracking, that is because the tensile stress introduced by drying shrinkage of concrete. The induced stresses resulting from drying shrinkage decreased not only the stiffness but also the diagonal cracking load of RC beams. Hereafter, the value obtained by dividing the diagonal cracking load $\left(V_{c}\right)$ by the effective cross-section area $(b d)$ is defined as shear tension strength $\left(\tau_{c}\right)$. 


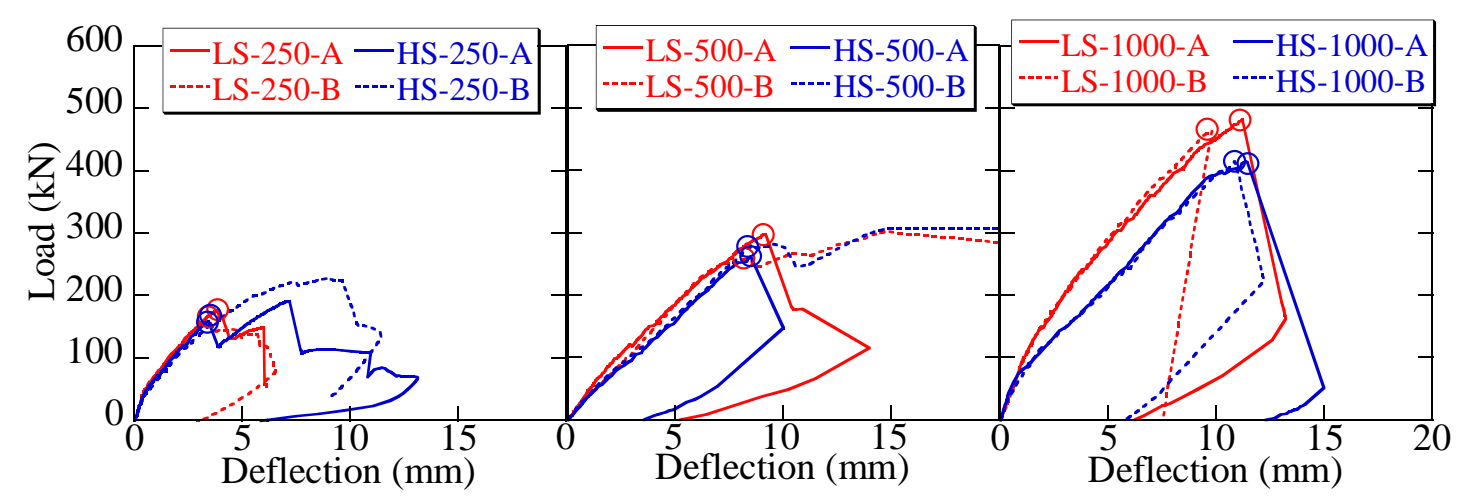

Figure 2 Load-deflection relationship

\section{Shear Tension Strength}

A summary of loading test results for each beam is given in Table 5, which shows the shear tension strength of all the RC beams. The averaged shear tension strength of HS beams with each effective depth was lower by up to $14 \%$ compared with that of LS beams with same effective depth.

\section{Size Effect}

Figure 3 shows the relationship between the shear tension strength and the effective depth of LS and HS beams, where the shear tension strength was normalized by dividing by the term of compressive strength in following equation (1) to compensate the difference of compressive strength in each beam. Eq. (1) proposed by Niwa et al. (1986) is the basic equation of JSCE design code (2018), and its accuracy has been widely confirmed. In addition, the regression curves for both beams obtained by the method of least squares are also shown. This result shows that the size effect of the shear tension strength became more sensitive due to the drying shrinkage of concrete, and the power of the effective depth for LS and HS beams were nearly $-1 / 4$ and $-1 / 3$, respectively.

$$
\tau_{c, c a l}=0.2 f_{c}^{1 / 3} \cdot(d / 1000)^{-1 / 4} \cdot\left(100 p_{s}\right)^{1 / 3} \cdot(0.75+1.4 /(a / d))
$$

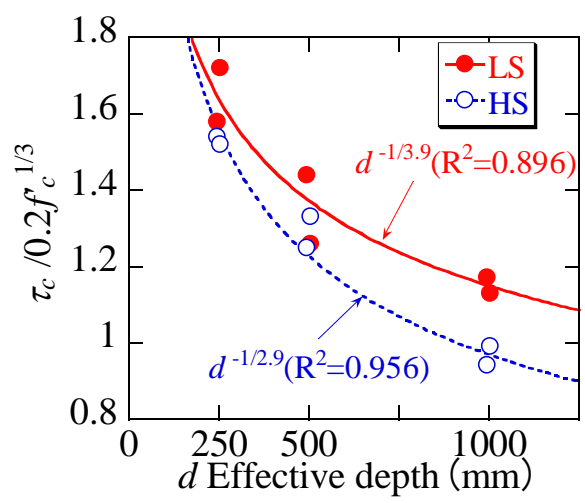

Figure 3 Size effect of shear tension strength 
From the above results, it was experimentally confirmed that the drying shrinkage of concrete decreases the shear tension strength of RC beams as well as enhances its size effect. In order to clarify these mechanisms, in following section, the effects of drying shrinkage of concrete on the crack and deformation of RC beams was investigated.

\section{Crack Width and Crack Propagation}

Figure 4 shows the relationship between the flexural crack width and the shear force, where the flexural crack width measured in the centre part of shear span. This is because the flexural crack in the centre part of shear span developed into flexural-shear cracks. As shown in this figure, the crack width of HS beams develops at a shear force lower than that of LAS beams, and increase markedly just after cracking. This could be because the compression strain in tension reinforcement introduced by concrete shrinkage is released by cracking and strain change in tension reinforcement before and after the load is larger in the HS beam than in the LS beam.

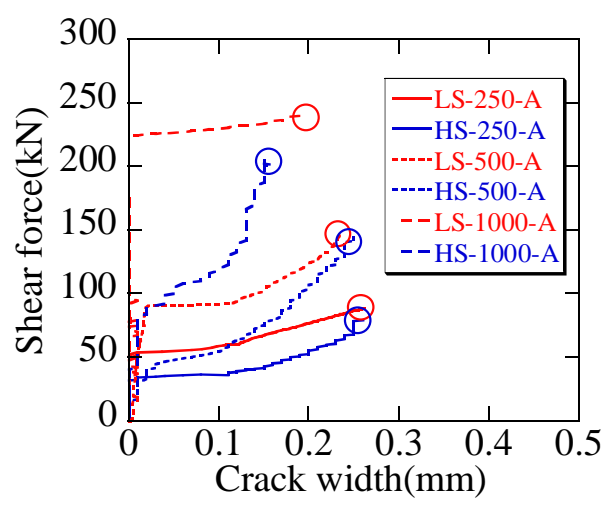

Figure 4 Relationship between the crack width and the shear force

Figure 5 shows the crack pattern when the shear stress of reaches $0.67 \mathrm{~N} / \mathrm{mm}^{2}$, which is the shear stress just before shear failure of specimens with the effective depth of $1000 \mathrm{~mm}$. The specimen is represented as equally size, in spite of their different dimension. In all the HS beams, the cracks of $0.1 \mathrm{~mm}$ or less due to drying shrinkage was observed in the vertical direction of the tension reinforcement from the bottom of specimen (The red line in Fig.6). The flexural cracks in the shear span of HS beams propagated deeper as compared with that of LS beams, which was more pronounced for specimens with higher effective depth, and some of them, the flexural cracks developed into the flexural-shear cracks. This could be because the influential area of crack distribution by tension reinforcement decreases with the higher effective depth. 


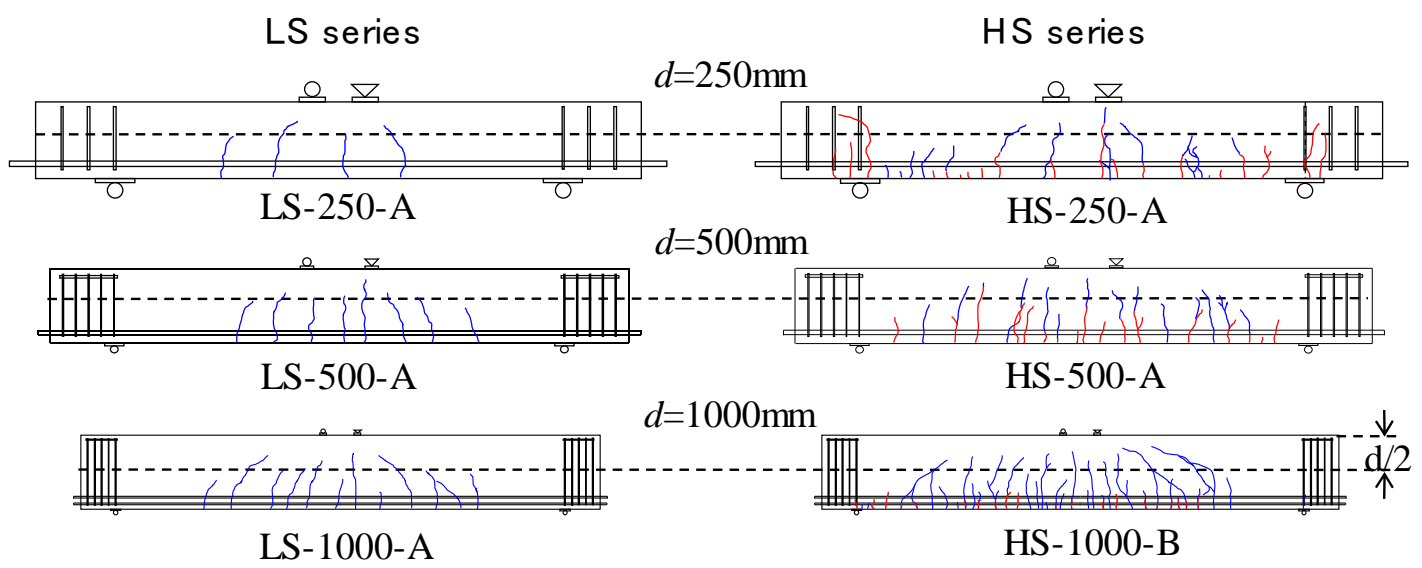

Figure 5 Crack patterns $\left(\tau=0.67 \mathrm{~N} / \mathrm{mm}^{2}\right)$

\section{Neutral Axis}

Figure 6 shows the relationship between the ratio of the neutral axis to the effective depth and the shear force, where the neutral axis was calculated by Bernoulli-Euler theory from the measured value obtained by upper and lower horizontal displacement shown in Fig.1. This figure shows that the neutral axis ratio of HS beams at the diagonal cracking is smaller than that of LS beams. This implies that the shrinkage of concrete contributes to reducing the thickness of the compression zone, which is one of the shear resistant factor.

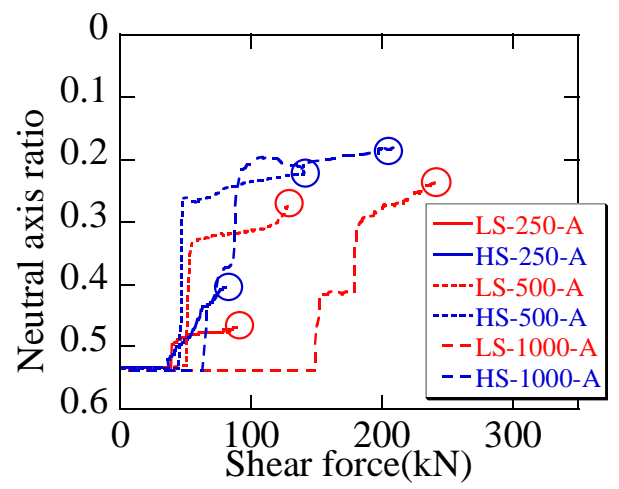

Figure 6 Relationship between the ratio of neutral axis and the shear force

\section{Shear Deformation}

Figure 7(a) shows the relationship between the shear stress-shear deformation, where the shear deformation is calculated from the measured value obtained by the diagonal displacement shown in Fig.1. The shear deformation in HS beams were larger than in LS beams. This could indicate that the shrinkage of concrete contributes to shear deformation. The shear deformation at the diagonal cracking shown by a circle in the figure increased as the effective depth increases. Figure 7(b) shows the relationship between the shear stress-shear strain, where the shear strain was calculated by dividing the shear deformation by the horizontal length in the displacement measurement section. The shear strain at the diagonal cracking decreased as the effective depth 
increases, which was opposite to the trend of the shear deformation. If the crack propagation behaviour is the same regardless of the effective depth, the shear strainshear deformation should show the similar trend. This may be because the cracks in the shear span were localized as the effective depth increases, but the increase in the non-localized were except for the cracks are dominant, conversely.

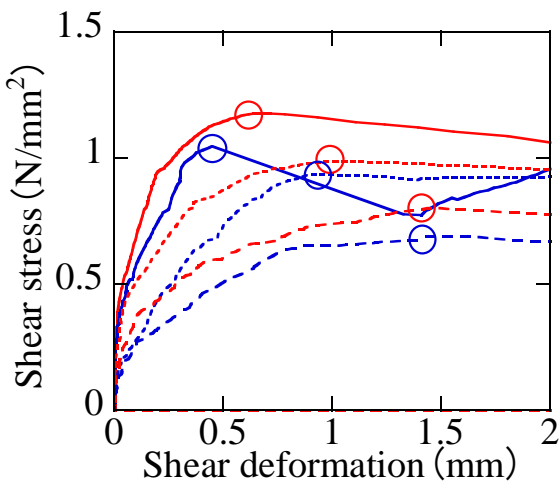

(a)Shear deformation

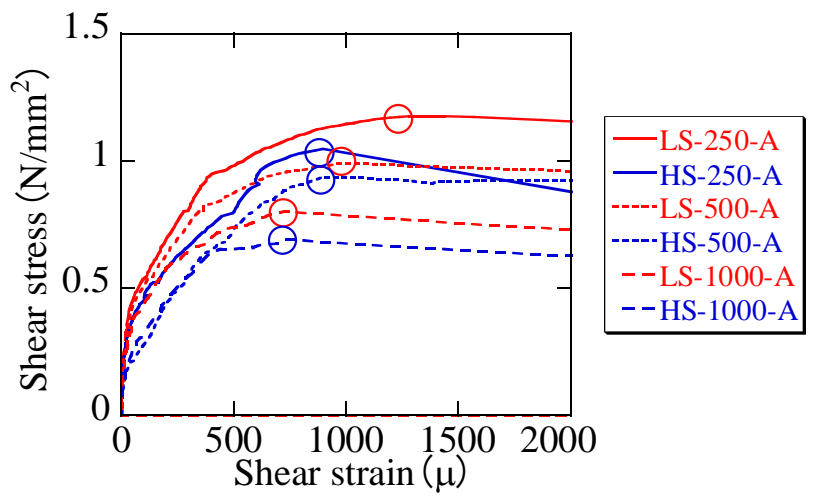

(b) Shear strain

Figure 7 Relationship between the shear deformation-shear strain and the shear stress

\section{Discussion of Mechanisms}

Based on the previous research and the experimental results in this paper, we discuss the effects of shrinkage and the effective depth on the shear tension strength of RC beam and its size effect. The localization of the cracks in the shear span was promoted as the effective depth increases. When the cracks were localized, the deformation concentrates in the primary crack and the crack width becomes relatively wider. That leads to reduce the shear resistance between the crack as well as the shear tension strength. Moreover, it was reported that the length of fracture process zone ahead of a crack is constant regardless of the size of specimen (Gustafsson and Hillerborg; 1988, Zink; 2000). When the effective depth of RC beam increases, the fracture process zone, which is a shear resistance factor, becomes smaller relatively, resulting in the shear tension strength decreases.

The compression strain in tension reinforcement introduced by concrete shrinkage is released by cracking and strain change in tension reinforcement before and after the load is larger in the HS beam than in the LS beam. The increase of the strain change in tension reinforcement makes the flexural crack width become wider, that leads to reduce a shear resistance between the flexural-shear crack. This could be one of factors of reducing the shear tension strength. As the effective depth increases, the shear tension strength decreases due to size effect, so the tension strain in tension reinforcement at diagonal cracking decreases. Therefore, even if the strain in tension reinforcement due to shrinkage is the same, the influence of shrinkage on the flexuralshear crack width could be relatively large as the effective depth increases. This could be the reason why the shrinkage of concrete makes the size effect enhance.

The increase of the diagonal crack width due to shrinkage makes the crack propagation deeply, shallow the neutral axial depth, decrease the compression zone which is the one of the shear resisting factor. 


\section{PROPOSED EQUATION FOR SHEAR TENSION STRENGTH CONSIDERING SHRINKAGE EFFECTS}

\section{A Concept for Evaluating Shear Tension Strength}

The compression strain in tension reinforcing bars is produced by drying shrinkage before loading, for this reason the magnitude of strain change in drying beam is larger than that of sealed beam, as shown in Figure 8, which is a conceptual diagram of strain change of reinforcement before and after loading for both beams. The increase of strain change should be functionally equivalent to the decrease of reinforcement ratio. Based on this hypothesis, a new concept of the equivalent tension reinforcement ratio given by the following Eq. (2) was proposed for estimating the effect of autogenous shrinkage on the shear tension strength in high-strength concrete beams (Sato and Kawakane 2008). This concept covers an estimation of shear tension strength of RC beams before yielding of reinforcement. Additionally, a similar concept for predicting flexural crack width and curvature of RC beams considering the concrete shrinkage before loading was already proposed. It was verified that the proposed concept improved the prediction accuracy compared with the conventional equation (Tanimura et al. 2007).

$$
p_{s, e}=\frac{\varepsilon_{s}}{\varepsilon_{s}-\varepsilon_{s 0, d e f}} p_{s}
$$

Where: $p_{s, e}$ : Equivalent tension reinforcement ratio, $p_{s}$ : Nominal tension reinforcement ratio, $\varepsilon_{s}$ : Tension reinforcement strain at the section $1.5 d$ distant from loading section in shear span at the diagonal cracking, $\varepsilon_{s 0, d e f}$. Tension reinforcement strain when concrete stress at the depth of reinforcement is zero, which is positive in tension and negative in compression.

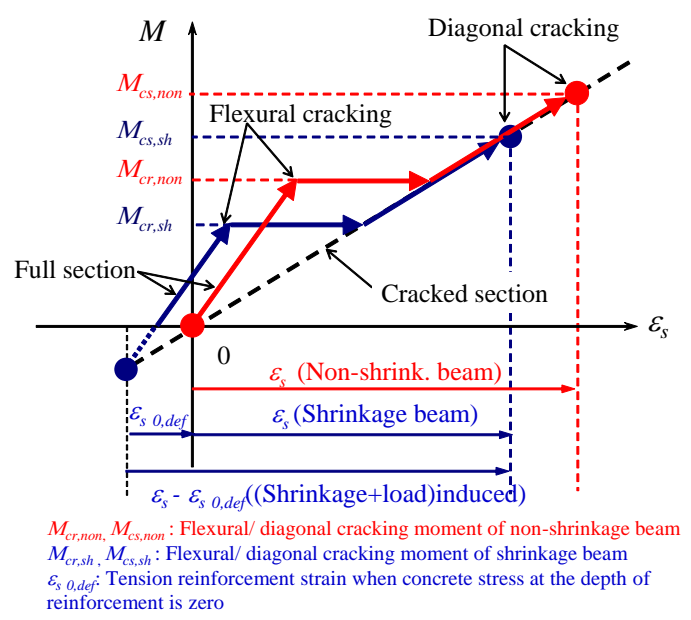

Figure 8 Concept of strain change in tension reinforcement due to drying shrinkage

Figure 9 shows the relationship between the effective depth and the shear tension strength obtained by Eq. (3) based on the equivalent tension reinforcement, in which 
the shear tension strength was assumed to be proportional to $1 / 3$ power of reinforcement ratio in accordance with Eq. (1).

$$
\tau_{c, e}=\tau_{c} \times\left(\frac{p_{s}}{p_{s e}}\right)^{1 / 3}
$$

As shown in this figure, the concept of the equivalent tension reinforcement ratio found to be effective in evaluating the shear tension strength independent of the shrinkage effect. The shear tension strength of RC beams followed to approximately $-1 / 4$ power of the effective depth, regardless of magnitude of concrete shrinkage.

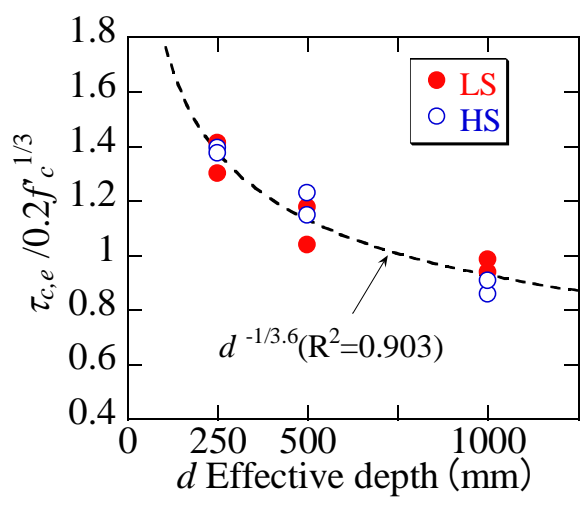

Figure 9 Shear tension strength based on equivalent tension reinforcement ratio

\section{Parametric Study}

A parametric study based on the equivalent tension reinforcement ratio was carried out, in order to evaluate the effects of concrete shrinkage on shear tension strength of RC beam. Table 6 lists the calculation conditions for the parametric study. The valuables of the drying shrinkage, the nominal tension reinforcement ratio and the effective depth were ranging from $0 \mu$ to $-500 \mu, 0.5 \%$ to $1.5 \%$ and $100 \mathrm{~mm}$ to $1000 \mathrm{~mm}$, respectively. A compression strain in tension reinforcement due to concrete shrinkage was calculated by Eq. (4). The shear tension strength was calculated by substituting the equivalent tension reinforcement ratio into Eq. (1).

Table 6 Calculation conditions

\begin{tabular}{c|c|c}
\hline Input parameters & unit & Values \\
\hline Compressive strength of concrete: $f_{c}^{\prime}{ }_{c}$ & $\mathrm{~N} / \mathrm{mm}^{2}$ & 30 \\
\hline Drying shrinkage of concrete: $\varepsilon_{c}$ & $\mu$ & $0,-300,-400,-500$ \\
\hline Nominal tension reinforcement ratio: $p_{s}$ & $\%$ & $0.5,1.0,1.5$ \\
\hline Effective depth of beam: $d$ & $\mathrm{~mm}$ & $100,250,500,750,1000$ \\
\hline Breadth of beam: $b$ & $\mathrm{~mm}$ & 300 \\
\hline Shear span to effective depth ratio: $a / d$ & - & 3 \\
\hline Young's modulus of concrete: $E_{c}$ & $\mathrm{kN} / \mathrm{mm}^{2}$ & 32 \\
\hline Young's modulus of tension reinforcement: $E_{s}$ & $\mathrm{kN} / \mathrm{mm}^{2}$ & 200 \\
\hline Creep coefficient of concrete: $\phi$ & - & 2.0 \\
\hline Ageing coefficient: $\chi$ & - & 0.8 \\
\hline
\end{tabular}




$$
\frac{\varepsilon_{s}}{\varepsilon_{c}}=1 /\left\{1+p_{s} \cdot \frac{\left(d-C_{g}\right)^{2}}{I_{c} / A_{c}} \cdot \frac{E_{s}}{E_{c}}(1+\chi \phi)\right\}
$$

Where: $C_{g}$ : Distance from compressive fiber to centroid of concrete section, $A_{c}, I_{c}$ : Cross section area and moment of inertia of concrete in section of beam

Figure 10 shows the relationship between the calculated shear tension strength and the effective depth. As shown in Fig.10(a), the shear tension strength decreases as the increase with concrete shrinkage. According to Fig.10(b), the size effect of reinforcement ratio on the shear tension strength is negligible while the shear tension strength is affected by the reinforcement ratio.

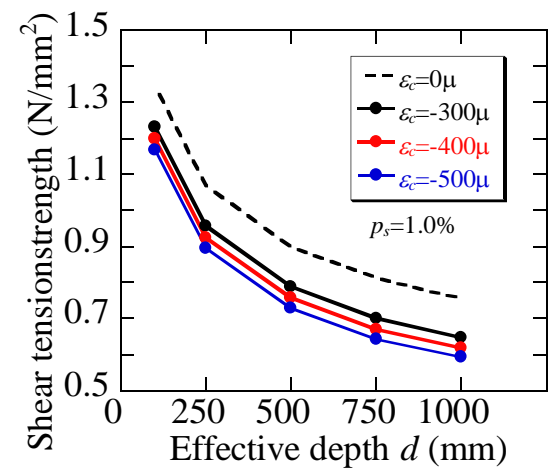

(a) Concrete shrinkage

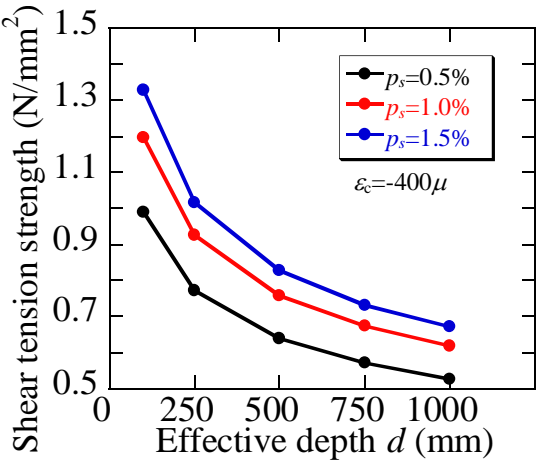

(b) Reinforcement ratio

Figure 10 Effect of the parameters on the shear tension strength calculated by Eq. (1) with the equivalent tension reinforcement ratio substituted

\section{CONCLUSIONS}

The effects of drying shrinkage on shear tension strength of normal-strength RC beam without web reinforcement as well as its size effect were experimentally investigated. The following conclusion can be drawn within the limit of the present study.

(1) The shear tension strength of RC beams exposed to drying condition decreased by up to $14 \%$ as compared with that of sealed beams.

(2) The size effect of shear tension strength of drying beams became more sensitive than that of sealed beams, which depended on $\mathrm{d}^{-1 / 4}$ and $\mathrm{d}^{-1 / 3}$ for sealed and drying beams, respectively.

(3) The increase of flexural-shear crack width and the decrease of compression zone were considered to be reasons the shear tension strength of RC beam decreased due to concrete shrinkage.

(4) A concept based on the equivalent tension reinforcement ratio incorporating the effect of strain change in reinforcement before loading due to concrete shrinkage was effective in evaluating the shear tension strength. 


\section{REFERENCES}

Gustafsson, P. J. and Hillerborg, A., (1988). "Sensitivity shear strength of longitudinally reinforced concrete beams to fracture energy of concrete." Journal of ACI, 286-294.

Hasegawa, T and Seki, H. (1984) "Effects of cracking due to drying shrinkage on reinforced concrete member" Proceedings of the Japan Concrete Institute, 6, 617-620. (in Japanese)

Hyodo, H., Sato, R., Kawai, K., and Nakarai, K., (2017). "Effects of drying shrinkage of concrete on shear behavior of reinforced concrete beams without shear reinforcement." Journal of Japan Society of Civil Engineers, E2 (Materials and Concrete Structures), 73(1), 50-69.

JSCE (2018), "Standard specifications for concrete structures-2017, Design."

Niwa, J., Yamada, K., Yokozawa, K. and Okamura, H. (1986).” Revaluation of the equation for shear strength of reinforced concrete beams without web reinforcement." Journal of Japan Society of Civil Engineers, 372, 167-176.

Sato, R. and Kawakane, H., (2008). "A new concept for the early age shrinkage effect on diagonal cracking strength of reinforced HSC beams." Journal of Advanced Concrete Technology, 6(1), 45-67.

Tanimura, M., Sato, R. and Hiramatsu, Y. (2007) "Serviceability Performance Evaluation of RC Flexural Members Improved by Using Low-Shrinkage HighStrength Concrete" Journal of Advanced Concrete Technology 5(2), 149-160.

Zink, M., (2000). "Diagonal shear cracking in slender concrete beams." LASER No. 5, University of Leipzig, 305-332. 